\title{
Is treatment termination safe in developmental dysplasia of the hip following ultrasonographic normalization?
}

\author{
Hakan Atalar, $\mathrm{MD}^{1}{ }^{10}$, Cüneyd Günay, $\mathrm{MD}^{2}$ (D) O. Şahap Atik, $\mathrm{MD}^{3}$ (D) \\ ${ }^{1}$ Department of Orthopedics and Traumatology, Gazi University Faculty of Medicine, Ankara, Turkey \\ ${ }^{2}$ Department of Orthopedics and Traumatology, Eskişehir Osmangazi University, Faculty of Medicine, Eskişehir, Turkey \\ ${ }^{3}$ Department of Orthopedics and Traumatology, Turkish Joint Diseases Foundation, Ankara, Turkey
}

Alpha $(\alpha)$ and beta $(\beta)$ angles are measured in the coronal section view on hip ultrasonography. These angles take into account acetabulum ossification seen on ultrasonography and it is accepted that the hip would not deteriorate after ultrasonographic normalization. ${ }^{[1]}$ In daily practice, the treatment for developmental dysplasia of the hip (DDH) is terminated, when an $\alpha$ angle of $\geq 60$ degrees (ultrasonographic normalization) is obtained. It is well known that hip ultrasonography shows ossification in soft tissues earlier than radiography.

In children undergoing DDH treatment, the osteochondral borders of the acetabulum visible on ultrasonography may not correspond with the osteochondral borders seen on radiographs. ${ }^{[2]}$ For these patients, it cannot be guaranteed that the ossification of the acetabular region seen on coronal sections of ultrasonography would be also calcified on X-ray. ${ }^{[2,3]}$ For instance, while the healing callus formation cannot

Received: April 25, 2021

Accepted: May 07, 2021

Published online: June 11, 2021

Correspondence: Cüneyd Günay, MD. Eskișehir Osmangazi Üniversitesi Tıp Fakültesi Ortopedi ve Travmatoloji Anabilim Dalı, 26040 Odunpazarı, Eskişehir, Türkiye.

E-mail: cungunay@hotmail.com

\section{Doi: $10.52312 / j d r s .2021 .206$}

Citation: Atalar H, Günay C, Atik OS. Is treatment termination safe in developmental dysplasia of the hip following ultrasonographic normalization?. Jt Dis Relat Surg 2021;32(2):521-522.

(02021 All right reserved by the Turkish Joint Diseases Foundation

This is an open access article under the terms of the Creative Commons Attribution-NonCommercial License, which permits use, distribution and reproduction in any medium, provided the original work is properly cited and is not used for commercial purposes (http://creativecommons.org/licenses/by-nc/4.0/) be seen on radiography during the early period of the fracture union process, it can be seen very well on ultrasonography (Figure 1a, b). Therefore, in this case, if the immobilization is discontinued and movement is initiated earlier according to ultrasonography, the fracture healing may not be guaranteed.

According to this hypothesis, the process mentioned above may be valid for the ossification of the cartilage acetabulum of infants treated for DDH.
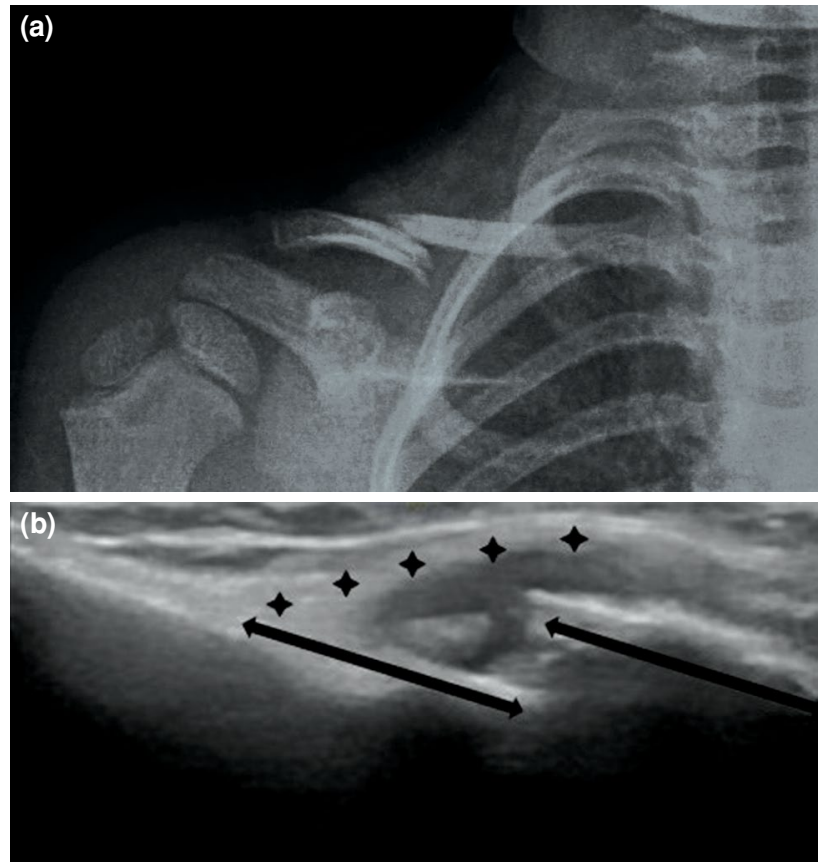

FIGURE 1. A five-year old male patient treated conservatively for a clavicle shaft fracture. (a) There was no sign of union on the radiography image in the second week of the treatment (b) while callus formation can be observed on ultrasonography $\leftrightarrow$ Segments of fractured clavicle. $\downarrow$ Callus of the fracture. 

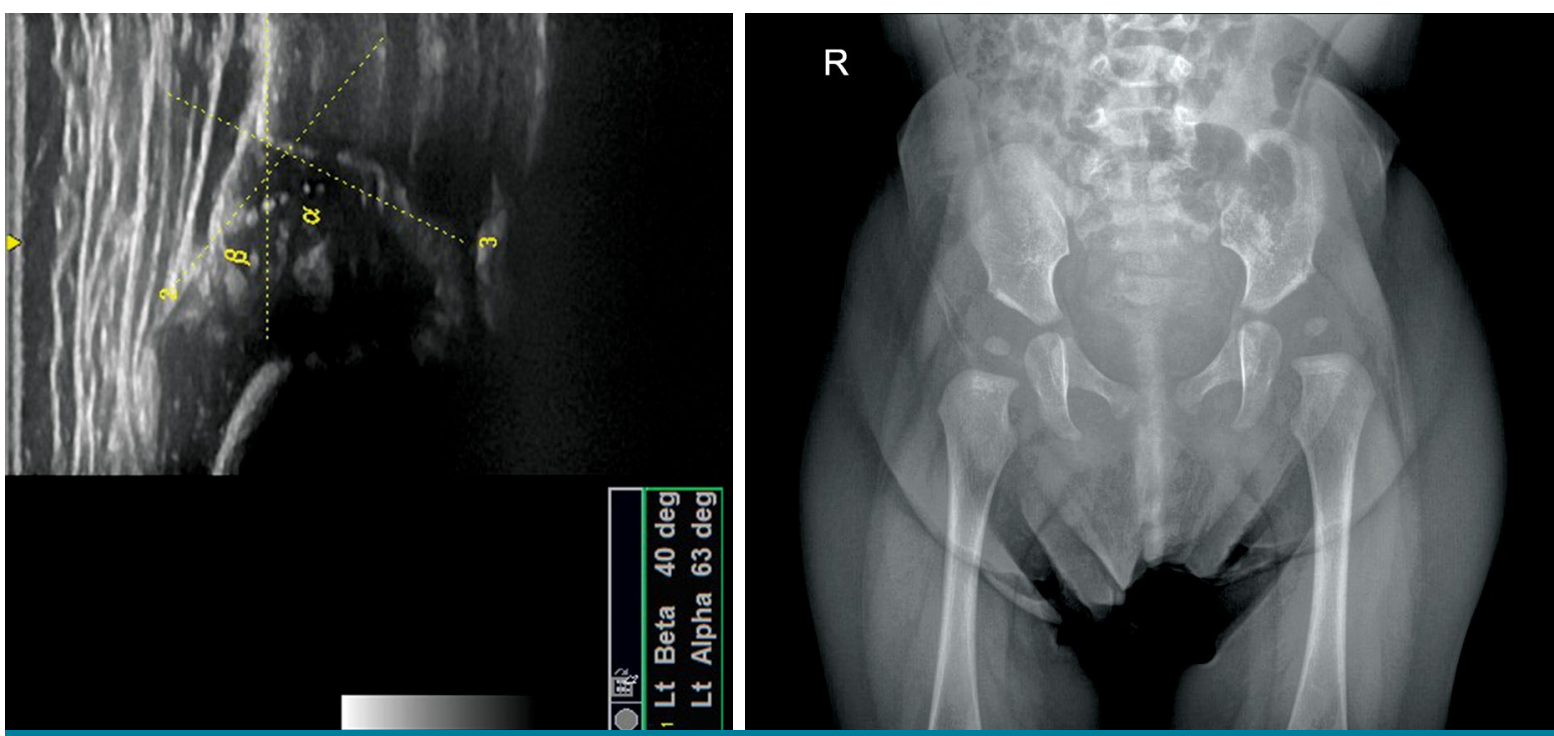

FIGURE 2. A six-month-old infant treated conservatively for dysplasia of the hip; (a) normal hip seen on ultrasonography, (b) while radiography shows continuing left hip dysplasia.

In the literature, a high rate of early acetabular dysplasia has been reported in infants, when the DDH treatment has been discontinued after the hips have appeared normal on ultrasonography. ${ }^{[3]}$

In conclusion, it may be safer to consider normalization on radiography rather than normalization on ultrasonography before terminating the treatment of DDH in infants (Figure 2a, b). We have been using Graf method in diagnosis and monitoring of treatment of DDH for many years. In our opinion, physicians should not hesitate to take pelvic radiography before ceasing DDH treatment. Additionally, even if the hip ultrasonography findings in the neonatal period are normal, we recommend taking pelvic radiography between 6 to 12 months before the child starts walking, in the presence of clinical examination findings or risk factors of DDH. Nevertheless, there is a need for prospective, controlled studies of larger series to elucidate this important issue.

\section{Declaration of conflicting interests}

The authors declared no conflicts of interest with respect to the authorship and/or publication of this article.

\section{Funding}

The authors received no financial support for the research and/or authorship of this article.

\section{REFERENCES}

1. Graf R, Mohajer M, Plattner F. Hip sonography update. Quality-management, catastrophes - tips and tricks. Med Ultrason 2013;15:299-303.

2. Atalar H, Gunay C, Turanli S, Koktener A. Discrepancy between ultrasonographic and radiographic findings in patients treated for developmental dysplasia of the hip; hip maturation on ultrasonography may not be consistent with radiographic hip maturation. J Pediatr Orthop B 2020;29:228-34.

3. David M, Robb C, Jawanda S, Bache C, Bradish C. Late recurrence of developmental dysplasia of the hip following Pavlik harness treatment until normal ultrasound appearance. J Orthop 2014;12:81-5. 